\title{
Defined Activity Subcategory Code
}

National Cancer Institute

\section{Source}

National Cancer Institute. Defined Activity Subcategory Code. NCI Thesaurus. Code C93759.

A coded value specifying a subdivision within a larger category of activities. 